\title{
A Xanthan-gum-like Polysaccharide from Acetobacter xylinum
}

\author{
By ROBERTO O. COUSO, LUIS IELPI AND MARCELO A. DANKERT* \\ Instituto de Incestigaciones Bioquimicas 'Fundacion Campomar', Facultad de Ciencias Exactas y \\ Naturales and Consejo Nacional de Investigaciones Cientificas y Tecnicas, Patricias Argentinas \\ 435 (1405), Buenos Aires, Argentina
}

(Received 25 September 1986; revised 2 March 1987)

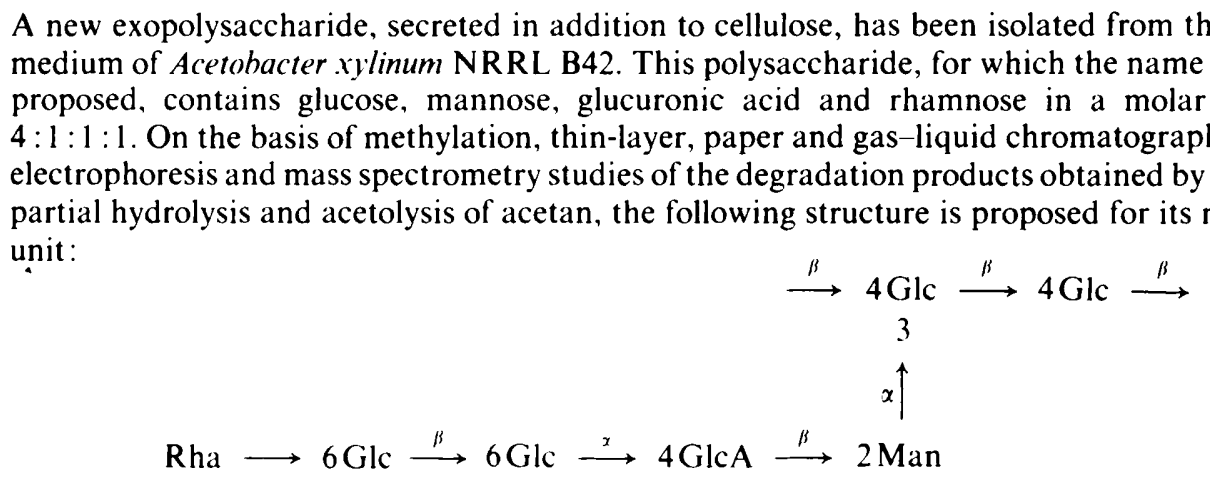

Since our previous work with this strain demonstrated the in vitro synthesis of a lipid-linked heptasaccharide with the same structure, the possibility of acetan being the result of its polymerization is discussed. One to two $O$-acetyl residues per repeating unit are also present in positions not yet determined.

\section{INTRODUCTION}

Acetohacter xylinum is a Gram-negative bacterium characterized by its capacity to synthesize cellulose. The in titro synthesis of cellulose by a cell-free system of this organism was first described by Glaser (1958) and later confirmed by several research groups (Aloni et al., 1983; Delmer, 1983). Work from this laboratory has shown that $A$. xylinum preparations are also able to synthesize, in ritro, a heptasaccharide linked to a polyprenol through a diphosphate bridge (Couso et al., 1982). [The linkages proposed by Couso et al. (1982) for the GlcA-Man bond and for the Man configuration have been revised in this communication.] The structure proposed for the heptasaccharide moiety, Rha(1-6)Glc $(\beta 1-6) \operatorname{Glc}(\alpha 1-4) \operatorname{GlcA}(\beta 1-2) \mathrm{Man}(\alpha 1-3) \mathrm{Glc}(\beta 1-4) \mathrm{Glc}$ is shown in Fig. 1 (frame I, solid lines). It is now reported that the same organism produces, in vivo, an exopolysaccharide containing this structure as repeating unit.

The $\beta$-1,4-substituted glucose at the 'reducing end' of the heptasaccharide is $\beta$-1,4-linked to the 'second glucose' of another repeating unit so as to form a $\beta$-1,4-chain in which a pentasaccharide branch appears every two glucoses (Fig. 1). A similar structure has been assigned to xanthan gum, an exopolysaccharide secreted into the culture medium by Xanthomonas campestris (Fig. 2) (Jansson et al., 1975; Melton et al., 1976). In this case the repeating unit is the pentasaccharide $\operatorname{Man}(\beta 1-4) \operatorname{Glc} A(\beta 1-2) \operatorname{Man}(\alpha 1-3) \operatorname{Glc}(\beta 1-4) G \operatorname{lc}$ and the glucose at its 'reducing end' is also $\beta$-1,4-linked to the 'second glucose' of another repeating unit in order to build a $\beta$-1,4-glucan chain containing a trisaccharide branch every two glucoses. In

Abhreviations: $R_{\mathrm{Al}}, R_{\text {tetrito-methylmannose }}: R_{\text {sorh }}, R_{\text {sorbitol }}$ 


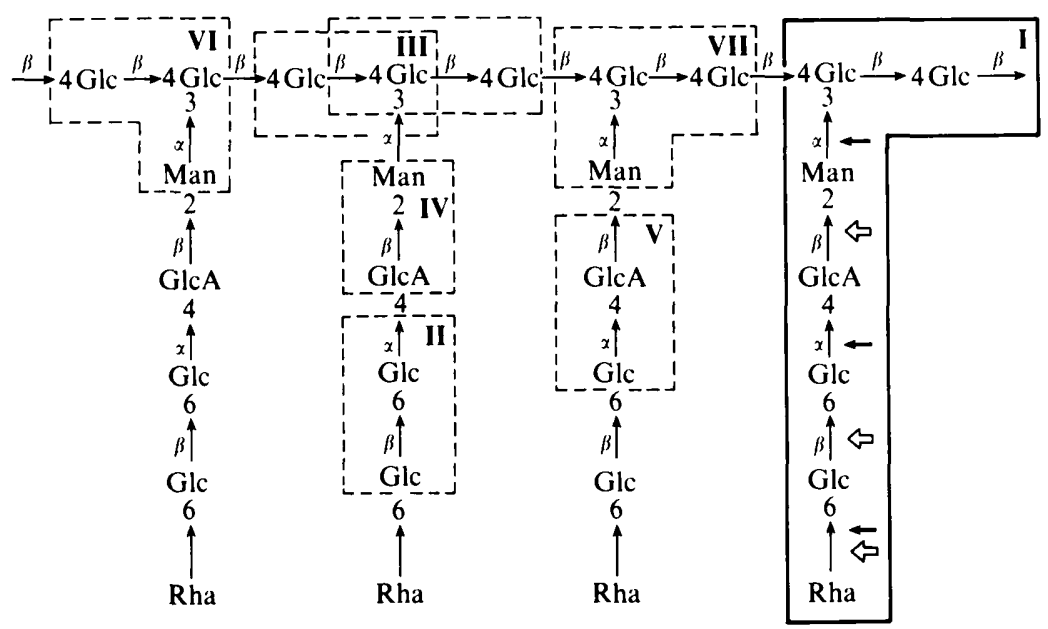

Fig. 1. Structure proposed for the exopolysaccharide acetan. The oligosaccharide I (encircled by solid lines) is the repeating unit. Oligosaccharides encircled by broken lines (II to VII) were characterized as products of different degradation procedures. Solid and open arrows indicate bonds labile to acid degradation and to acetolysis, respectively.

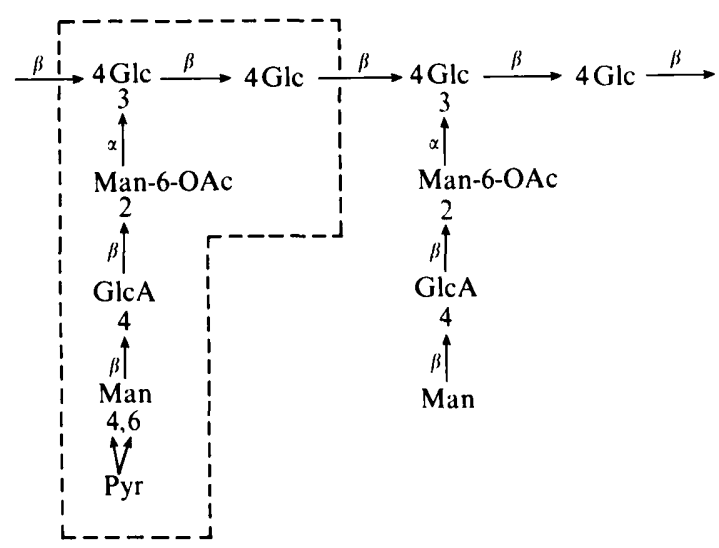

Fig. 2. Proposed structure for xanthan gum. The broken lines encircle a fully substituted pentasaccharide repeating unit. The main chain is a $\beta$-1,4-glucan.

addition, the internal mannose of xanthan gum is acetylated at position 6 and about half of the external mannoses contain a 4-6 pyruvic ketal residue (Jansson et al., 1975; Melton et al., 1976; Sandford et al., 1977). In spite of the complexity of the two polysaccharides, they have the same basic structure: both can be considered to be 'substituted celluloses' as both contain a $\beta$-1,4glucose main chain. For the $A$. xylinum product the name acetan is proposed.

The following study is mainly a comparative one in which acetan fragments are compared to oligosaccharides obtained by partial degradation of the $A$. xylinum heptasaccharide diphosphate prenol and xanthan gum.

\section{METHODS}

Isolation of acetan. Acetobacter xylinum NRRL B42 was grown in unshaken cultures as described by Hestrin \& Schramm (1954). This technique favours the formation of a surface pellicle which contains most of the cells and the cellulose. The pellicles were gently washed with $0.01 \mathrm{M}$-sodium phosphate/citrate buffer, $\mathrm{pH} 6.0$, and then disrupted in a blender. The suspension obtained was filtered through several layers of cheesecloth to retain the 
cellulose fibres and the filtrate was centrifuged at $23300 \mathrm{~g}$ for $15 \mathrm{~min}$ to remove the cells, as described by Garcia $\mathrm{et}$ al. (1974). Occasionally, cells were grown in the same medium with rotary shaking (200 r.p.m.) for $48 \mathrm{~h}$. The cultures were directly filtered through cheesecloth, and the filtrate was centrifuged as above. In both cases, the clear supernatant was used as source of polysaccharide. Solid $\mathrm{KCl}$ to a final concentration of $1 \%(\mathrm{w} / \mathrm{v})$ was added and the polysaccharide was precipitated with 2 vols $96 \%(\mathrm{v} / \mathrm{v})$ ethanol. The acetan fibres were removed by rolling them around a glass rod and then redissolved in distilled water (a tenth of the initial supernatant volume). The $\mathrm{KCl}$ concentration was brought to $1 \%(\mathrm{w} / \mathrm{v})$ and the polysaccharide was again precipitated by adding $2 \mathrm{vols} 96 \%$ $(\mathrm{v} / \mathrm{v})$ ethanol. This procedure was repeated six or seven times and the final solution was dialysed against distilled water for $24-48 \mathrm{~h}$ and lyophilized. Solutions of this material were very viscous and slightly opalescent. Clear solutions were obtained either by ultracentrifugation (Holzwarth, 1976) or, more simply, by centrifuging diluted solutions of polysaccharide $\left(3 \mathrm{mg} \mathrm{ml}^{-1}\right.$ or less) at $65000 \mathrm{~g}$ for $2 \mathrm{~h}$ at $4{ }^{\circ} \mathrm{C}$. The supernatants were lyophilized. The yield of acetan was $200-300 \mathrm{mg}$ ( $\mathrm{g}$ wet weight of bacteria) ${ }^{-1}$. Unshaken cultures produced less polysaccharide than shaken cultures.

Acid hydrolysis. The polysaccharide was partially hydrolysed in $0 \cdot 1 \mathrm{M}-\mathrm{HCl}$ in the presence of Dowex $50 \mathrm{~W}-\mathrm{X} 8$ $\left(\mathrm{H}^{+}\right.$form) resin, in sealed tubes at $100{ }^{\circ} \mathrm{C}$ for $1 \mathrm{~h}$ (Davidson, 1966). The supernatant was removed and the resin washed several times with water. The washings were combined with the hydrolysate. Total hydrolysis was achieved by using $1 \mathrm{M}-\mathrm{HCl}$ at $100^{\circ} \mathrm{C}$ for $20-24 \mathrm{~h}$, in sealed tubes. In both cases, the hydrolysed samples were repeatedly brought to dryness to remove the acid.

Acetolysis. Partial acetolysis was done either as by Kocourek \& Ballou (1969) with minor modifications, or as by Lawson \& Symes (1977), as indicated in each experiment.

Methylation analysis. The method of Hakomori was used, as described by Sandford \& Conrad (1966). Samples without glucuronic acid were directly hydrolysed in $1 \mathrm{M}-\mathrm{HCl}$ at $100^{\circ} \mathrm{C}$ for $4 \mathrm{~h}$, and then brought to dryness to eliminate the $\mathrm{HCl}$. Samples containing glucuronic acid were first treated with $90 \%(\mathrm{v} / \mathrm{v})$ formic acid at $100^{\circ} \mathrm{C}$ for $1 \mathrm{~h}$, then concentrated under vacuum, and the hydrolysis was completed with $0.25 \mathrm{M}-\mathrm{H}_{2} \mathrm{SO}_{4}$, at $100{ }^{\circ} \mathrm{C}$, for $16 \mathrm{~h}$. The hydrolysates were desalted with Dowex $1-\mathrm{HCO}_{3}{ }^{-}$columns $(0.5 \times 7 \mathrm{~cm})$. The partially methylated sugars were recovered by washing the column successively with water $(4 \mathrm{ml})$ methanol/water $(1: 1, \mathrm{v} / \mathrm{v})(4 \mathrm{ml})$ and methanol $(4 \mathrm{ml})$, and submitted to thin-layer chromatography (TLC).

The samples for gas-liquid chromatography (GLC) were converted to the alditol acetate derivatives. They were reduced in $0.15 \mathrm{ml} 0.2 \mathrm{M}-\mathrm{NaBH}_{4}, \mathrm{pH} 10$, at room temperature for $14 \mathrm{~h}$, and the reaction was ended by addition of $0.015 \mathrm{ml}$ acetic acid. Borate was removed by repeated evaporation with $1 \%(\mathrm{v} / \mathrm{v})$ acetic acid in methanol. The reduced samples were desalted with a mixed-bed Amberlite MB-3 resin column $(0.7 \times 11 \mathrm{~cm})$. Acetylation was performed in pyridine/acetic anhydride $(1: 1, \mathrm{v} / \mathrm{v})$ at $100^{\circ} \mathrm{C}$ for $1 \mathrm{~h}$.

Reduction of glucuronic acid (Valent et al., 1980). Tetrahydrofuran $(8.5 \mathrm{ml})$ and sodium boro $\left[{ }^{3} \mathrm{H}\right]$ hydride $(30 \mathrm{mg}$, New England Nuclear; $46.9 \mathrm{mCi} \mathrm{mmol}^{-1}, 1.74 \mathrm{GBq} \mathrm{mmol}^{-1}$ ) were added to methylated acetan (approx. $10 \mathrm{mg}$ ), dissolved in $3.1 \mathrm{ml}$ ethanol. The solution was left at room temperature for $18 \mathrm{~h}$ and then treated at $70^{\circ} \mathrm{C}$ for $1 \mathrm{~h}$. Reduction was ended by dropwise addition of glacial acetic acid until no more gas evolved. A solution (10 ml) of $10 \%(\mathrm{v} / \mathrm{v})$ acetic acid in methanol was then added and the mixture was brought to dryness in a rotary evaporator. This operation was repeated three times. The ${ }^{3} \mathrm{H}$-labelled methylated polysaccharide was dissolved in $10 \mathrm{ml}$ water, dialysed and freeze dried. The product obtained was methylated again and hydrolysed as described above.

Free glucuronic acid was reduced to the respective alditol, and acetylated as described by Jones \& Albersheim (1972).

Chromatography and electrophoresis. Paper chromatography and electrophoresis were done using Whatman no. 1 paper as previously described (Garcia et al., 1974). The following solvents were used: A, 1.2 M-pyridinium acetate buffer $\mathrm{pH} 6.5$; B, $0.05 \mathrm{M}$-sodium borate $\mathrm{pH} 9.8 ; \mathrm{C}, 0.1 \mathrm{M}$-sodium molybdate buffer $\mathrm{pH} \mathrm{5.0;} \mathrm{D,} \mathrm{propan-2-}$ ol/acetic acid/water (27:4:9, by vol.); E, butan-l-ol/pyridine/water $(6: 4: 3$, by vol.).

Reducing substances were located with alkaline silver nitrate (Trevelyan et al., 1950) and radioactive areas with a radiochromatogram scanner (Packard, model 7201). UV-absorbing compounds were detected with a Mineralight UV lamp. Partially methylated mannose, glucose and rhamnose species were separated by TLC on silica gel $G$ plates $\left(250 \mu \mathrm{m}\right.$ thick, Merck) in solvents $\mathrm{F}$ [benzene/acetone/water $/ \mathrm{NH}_{4} \mathrm{OH}$ (sp. gr. 0.91 ) $\left(50: 200: 1: 1 \cdot 35\right.$, by vol.)] and $\mathrm{G}$ [benzene/acetone/water/ $\mathrm{NH}_{4} \mathrm{OH}$ (sp. gr. 0.91$)(50: 200: 3: 1 \cdot 5$, by vol.)]. The samples were located in two different ways. The plates were either sprayed with $5 \%(\mathrm{v} / \mathrm{v}) \mathrm{H}_{2} \mathrm{SO}_{4}$ in ethanol and heated at $120^{\circ} \mathrm{C}$ for $10 \mathrm{~min}$ (Li et al., 1978), or directly heated at $160^{\circ} \mathrm{C}$ for $15 \mathrm{~min}$, and the spots photographed under UV light (Alperin et al., 1983).

Labelled compounds were located by radioscanning as above, or by autoradiography using Kodak X-Omat AR films (X AR-5).

A Hewlett-Packard 5830 A gas chromatograph, equipped with a glass column $(180 \times 0.2 \mathrm{~cm})$ packed with $3 \%$ ECNSS-M on Chromosorb Q, and a flame-ionization detector, was used to analyse the alditol acetates of the free sugars. The samples were run isothermally at $180^{\circ} \mathrm{C}$ with $\mathrm{N}_{2}$ as carrier gas. Under these conditions the following retention times $(\mathrm{min})$ were obtained: rhamnose, 4.66; mannose, 20.93; and glucose 29.89. 
Gas-liquid chromatography/mass spectrometry (GLC-MS). The samples containing partially methylated sugars were fractionated by TLC with solvent F. Several plates were run simultaneously and one of them was developed to locate the different components. The apropriate areas in the other plates were scraped off and the pooled silica powder extracted three times $(0.5 \mathrm{ml}$ each) with chloroform $/$ methanol $(1: 1, \mathrm{v} / \mathrm{v})$. The purity of each component was checked by running a portion in the same TLC system. The corresponding alditol acetates, prepared as described above, were analysed with a Varian Aerograph series 1400 gas chromatograph, coupled to a Varian Mat model CH7A mass spectrometer equipped with a Varian model V76 data processor. A glass column $(120 \times 0.2 \mathrm{~cm})$ packed with $3 \%$ E.SCNSS-M on Chromosorb Q was used with $\mathrm{He}$ as the carrier gas.

Enzyme treatments. The reaction mixture for degradation with $\beta$-glucuronidase from bovine liver (Sigma) contained : $10 \mu \mathrm{mol}$ sodium acetate buffer $\mathrm{pH} 4.5$. the oligosaccharide under study and $25 \mu \mathrm{g}$ ( 16.4 units) of enzyme in a total volume of $0.1 \mathrm{ml}$. Incubations were performed at $37^{\circ} \mathrm{C}$, under a toluene atmosphere, for $14 \mathrm{~h}$. Reactions were ended by adding 1 vol. ethanol. The supernatant was brought to dryness and analysed by paper electrophoresis with solvent $A$.

Treatments with $\alpha$-mannosidase from Jack bean (Sigma, type III, 0.65-1.3 units) were carried out in $50 \mathrm{~mm}$ sodium citrate buffer $\mathrm{pH} 4.5$ (total volume $0.05 \mathrm{ml}$ ) at $25^{\circ} \mathrm{C}$ for $18 \mathrm{~h}$. The reactions were ended by adding 1 vol. ethanol and the supernatants were desalted on Amberlite MB-3 (acetate form). With this enzyme preparation $p$ nitrophenyl $\alpha$-mannoside $(0.25 \mu \mathrm{mol})$ was completely hydrolysed in a $30 \mathrm{~min}$ incubation while the $\beta$-anomer was not degraded even after overnight treatment.

Sugar determination. Total carbohydrate was determined by the phenol/sulphuric acid method (Smith \& Montgomery, 1956), rhamnose according to Dische \& Shettles (1948), uronic acids as described by Blumenkrantz \& Asboe-Hansen (1973), and glucose with glucose oxidase (Lloyd \& Whelan, 1969). Acetate was measured by the method of Hestrin (1949) and pyruvate by the Sloneker \& Orentas method as modified by Sutherland (1969).

Chemicals. The disaccharides $\left[{ }^{1+} \mathrm{C}\right] \mathrm{GlcA}(\beta 1-2) \mathrm{Man}$ and $\mathrm{Glc}(\alpha 1-4)\left[{ }^{1+} \mathrm{C}\right] \mathrm{GlcA}$ were prepared by partial hydrolysis and partial acetolysis, respectively, of the hexasaccharide $\operatorname{Glc}(\beta 1-6) \operatorname{Glc}(\alpha 1-4)\left[{ }^{1+} \mathrm{C}\right] \mathrm{Glc} A(\beta 1-2) \mathrm{Man}$ $(\alpha 1-3) \mathrm{Glc}(\beta 1-4)$ Glc obtained in vitro by using an $A$. xylinum enzyme preparation (Couso et al., 1982).

The trisaccharide $\operatorname{Man}(\alpha 1-3) \mathrm{Glc}(\beta 1-4) \mathrm{Glc},{ }^{1+} \mathrm{C}$-labelled in either the mannose or the glucose moieties, was prepared as described, using either $A$. xylinum (Couso et al., 1980) or $X$. campestris enzymes (lelpi et al., 1981).

$\left[{ }^{1+} \mathrm{C}\right]$ Glucose-labelled xanthan gum was synthesized in vitro (Ielpi et al., 1981). This polysaccharide was used to obtain a mixture of $\operatorname{Man}(\alpha 1-3)\left[{ }^{1+} \mathrm{C}\right] \mathrm{Glc}(\beta 1-4)\left[{ }^{1+} \mathrm{C}\right] \mathrm{Glc}$ and $\left[{ }^{1+} \mathrm{C}\right] \mathrm{Glc}(\beta 1-4)[\mathrm{Man}(\alpha 1-3)]\left[{ }^{1+} \mathrm{C}\right] \mathrm{Glc}$ trisaccharides by partial acetolysis, as described by Lawson \& Symes (1977).

Maltose, sophorose, gentiobiose or laminaribiose were first methylated and then acid hydrolysed for preparing tetra- and the respective tri- $O$-methyl-glucose derivatives. $\mathrm{Di}$ - and mono- $O$-methyl substituted glucoses were purchased from Supelco. 2,6,-Di- $O$-methyl[ $\left[{ }^{4} \mathrm{C}\right]$ glucose was obtained by methylation of $\left[{ }^{14} \mathrm{C}\right]$ glucose-labelled xanthan gum. 3,4,6-Tri-O-methyl[ $\left.{ }^{14} \mathrm{C}\right]$ mannose was kindly provided by $\mathrm{G}$. Lederkremer. 2,3,4,-Tri-Omethylrhamnose and 2,3,4,6-tetra- $O$-methylmannose were prepared from the free sugars.

\section{RESULTS}

\section{Sugar composition}

The acetan was isolated and purified and the purity of the polysaccharide was checked by gel filtration. The phenol/sulphuric-positive material was excluded as a single peak from Sephadex G-100 and Bio-Gel A-1.5 m columns and included in a Bio-Gel A-5 m column, indicating an apparent $M_{\mathrm{r}}$ of about $2 \times 10^{6}$ (data not shown).

Total acid hydrolysates were analysed by paper chromatography with solvents $\mathrm{D}$ and $\mathrm{E}$, which showed the presence of glucose, mannose, rhamnose and uronic acid. The latter was identified as glucuronic acid by paper electrophoresis with buffers A and B and by GLC of the respective reduced alditol acetate (Jones \& Albersheim, 1972). GLC of the total acid hydrolysate confirmed the presence of glucose, mannose and rhamnose. Rhamnose and glucuronic acid were measured in the intact polysaccharide and in the acid hydrolysate (Table 1). Glucose was assayed only in the acid hydrolysate. The glucose/mannose ratio was measured by GLC of the respective alditol acetates (Table 1), a technique that gives low values for the rhamnose derivative (Lindberg, 1972). All these results taken together indicated that acetan contained glucose, mannose, glucuronic acid and rhamnose in the molar ratio $4: 1: 1: 1$ (Table 1), identical to that found for the heptasaccharide diphosphate prenol synthesized in vitro by $A$. xylinum preparations (Couso et al., 1982). 


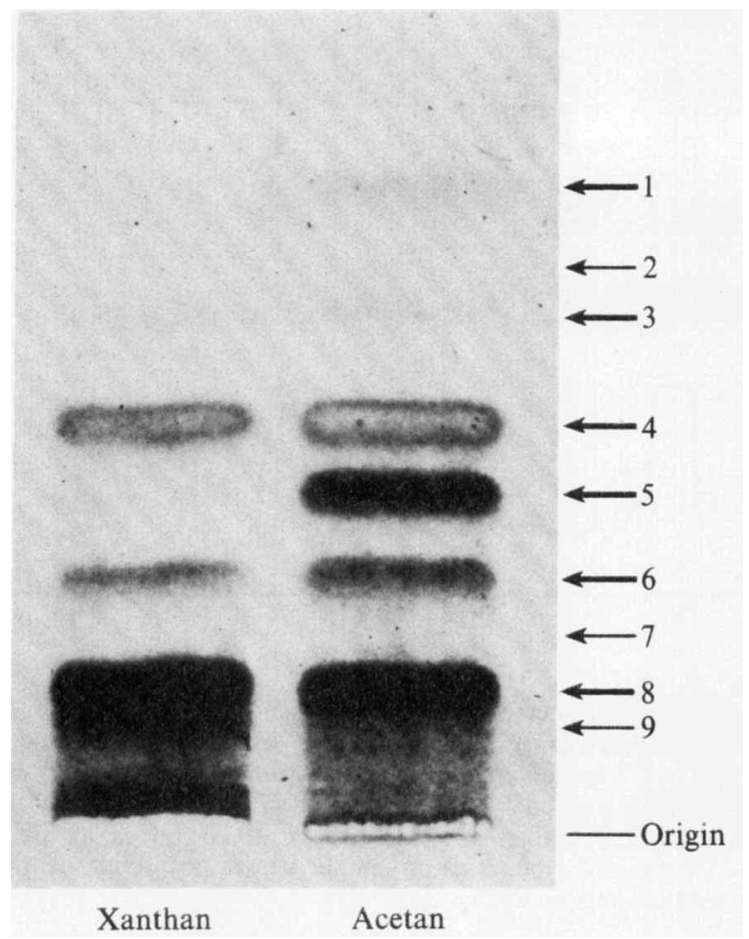

Fig. 3. TLC of the products of methylation of acetan and xanthan gum. Samples of each polysaccharide $(10 \mathrm{mg}$ ) were methylated and hydrolysed (see Methods) and the products analysed by TLC with solvent F. The standards were: (1) 2,3,4-tri-O-Me-Rha; (2) 2,3,4,6-tetra-O-Me-Glc: (3) 2,3,4,6-tetra- $O$-MeMan; (4) 2,3,6-tri-O-Me-Glc; (5) 2,3,4-tri-O-Me-Glc; (6) 3,4,6-tri-O-Me-[ $\left.{ }^{1+} \mathrm{C}\right] \mathrm{Man}$; (7) 2,4-di-O-MeGlc: (8) 2,6-di-O-Me- $\left[{ }^{1+} \mathrm{C}\right] \mathrm{Glc} ;(9)$ 2,3,-di-O-Me-Man. Standards with the mobilities of acetan products are indicated with thick arrows. Unlabelled compounds were located by the UV method (Alperin et al., 1983) and radioactive standards 6 and 8 by autoradiography.

\section{Table 1. Composition of acetan}

In the intact polysaccharide glucuronic acid and rhamnose were determined as described by Blumenkrantz \& Asboe-Hansen (1973) and Dische \& Shettles (1948), respectively. After acid hydrolysis in $1 \mathrm{M}-\mathrm{HCl}$, glucuronic acid and rhamnose were determined as above, and glucose was assayed with glucose oxidase. The molar ratios are arbitrarily referred to glucuronic acid. The alditol acetates prepared from acid hydrolysates were fractionated by GLC. The peak areas were compared, assigning a value of 4 to the glucose peak.

\begin{tabular}{|c|c|c|c|c|}
\hline \multirow[b]{2}{*}{ Sample } & \multicolumn{4}{|c|}{ Molar ratios } \\
\hline & Glucose & Mannose & $\begin{array}{l}\text { Glucuronic } \\
\text { acid }\end{array}$ & Rhamnose \\
\hline Acetan & ND & ND & 1.00 & 0.95 \\
\hline Hydrolysed acetan & 4.05 & ND & $1 \cdot 00$ & 1.03 \\
\hline Alditol acetates & $4 \cdot 00$ & 0.97 & ND & 0.58 \\
\hline
\end{tabular}

ND. Not determined.

\section{Methylation studies}

Permethylated acetan, hydrolysed and analysed by TLC, generally produced five compounds (Fig. 3). They had the mobilities of 2,6-di- $O$-methylglucose, 2,3,4-tri- $O$-methylglucose, 2,3,6-tri$O$-methylglucose, 3,4,6-tri-O-methylmannose and 2,3,4-tri- $O$-methylrhamnose, indicating that a glucose was branched at positions 3 and 4 and that rhamnose was the only terminal sugar, in 


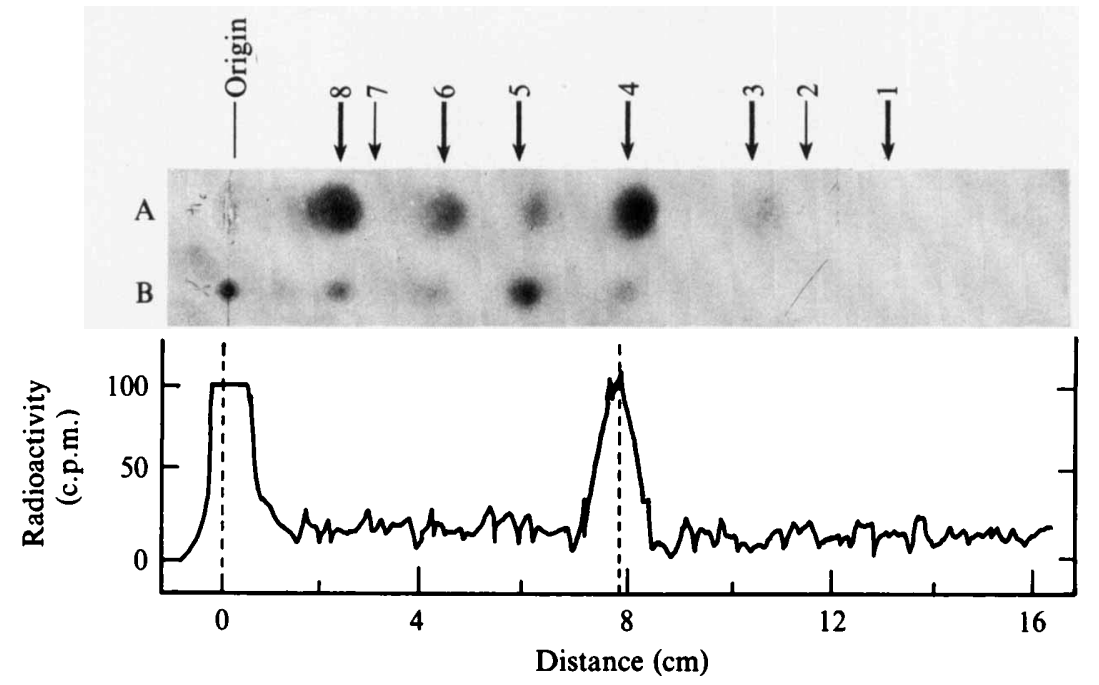

Fig. 4. TLC of permethylated acetan and glucuronic-acid-reduced permethylated acetan products. Permethylated acetan $(10 \mathrm{mg})$ was reduced with boro $\left[{ }^{3} \mathrm{H}\right]$ hydride, methylated again and hydrolysed as described in Methods (A). Another sample of permethylated acetan (10 mg) was hydrolysed directly (B). The hydrolysis products were analysed by TLC with solvent $F$. The methylated derivatives in both samples were located by the UV method (Alperin et al., 1983) (the rhamnose derivative produced a very faint spot) and the tritiated products from sample $A$ by radioactivity scanning (lower frame). The standards ( 1 to 8 ) are the same as in Fig. 3.

agreement with the proposed structure (Fig. 1). These products also showed that in the original polysaccharide there are glucose residues monosubstituted at positions 4 and 6 , and mannose residues substituted at carbon 2 . The identity of all these methylated compounds was confirmed by GLC-MS of the respective alditol acetates (not shown). Xanthan gum submitted to the same procedure produced a similar pattern (Fig. 3); the main differences were the absence of 2,3,4tri- $O$-methylrhamnose and 2,3,4-tri- $O$-methylglucose and the presence of 2,3-di-O-methylmannose, almost hidden by the strong 2,6-di- $O$-methylglucose band.

Occasionally, a sixth compound, with the mobility of 2,3,4,6-tetra- $O$-methylmannose, was detected among the acetan permethylation products (Fig. 3, band 3). Its presence was attributed to a cleavage of the glucuronic-mannose linkage generating a terminal mannose, as already reported for the permethylation of xanthan gum (Jansson et al., 1975) and mucoran, since polysaccharides containing uronic acid residues substituted at C-4 may be extensively degraded during methylation (Bartnicki-Garcia \& Lindberg, 1972).

The presence of methylated glucuronic acid was determined in a different way. Permethylated acetan was reduced with boro $\left[{ }^{3} \mathrm{H}\right]$ hydride in order to convert the glucuronate methyl ester residue into the $\left[6-{ }^{3} \mathrm{H}\right]$ glucose derivative. The tritiated polysaccharide was permethylated again, acid hydrolysed, and analysed by TLC as before (Fig. 4). In addition to the radioactivity at the origin, a peak was detected coincident with the spot of 2,3,6-tri-Omethylglucose, indicating that in the non-reduced acetan, glucuronic acid was substituted at carbon 4, as proposed (Fig. 1).

\section{Partial degradation of acetan}

To ascertain the sequence in which the different sugars were linked and knowing the positions at which they were substituted, efforts were made to obtain oligosaccharides that were easy to characterize. Previous work on the structure of the heptasaccharide diphosphate prenol had shown that some of the glycosidic linkages were easily broken by acid hydrolysis but resistant to acetolysis and vice versa, producing in each case disaccharides of known structure (Fig. 1) (Couso et al., 1982). The same procedures were then applied to acetan and the compounds obtained compared with known standards. 


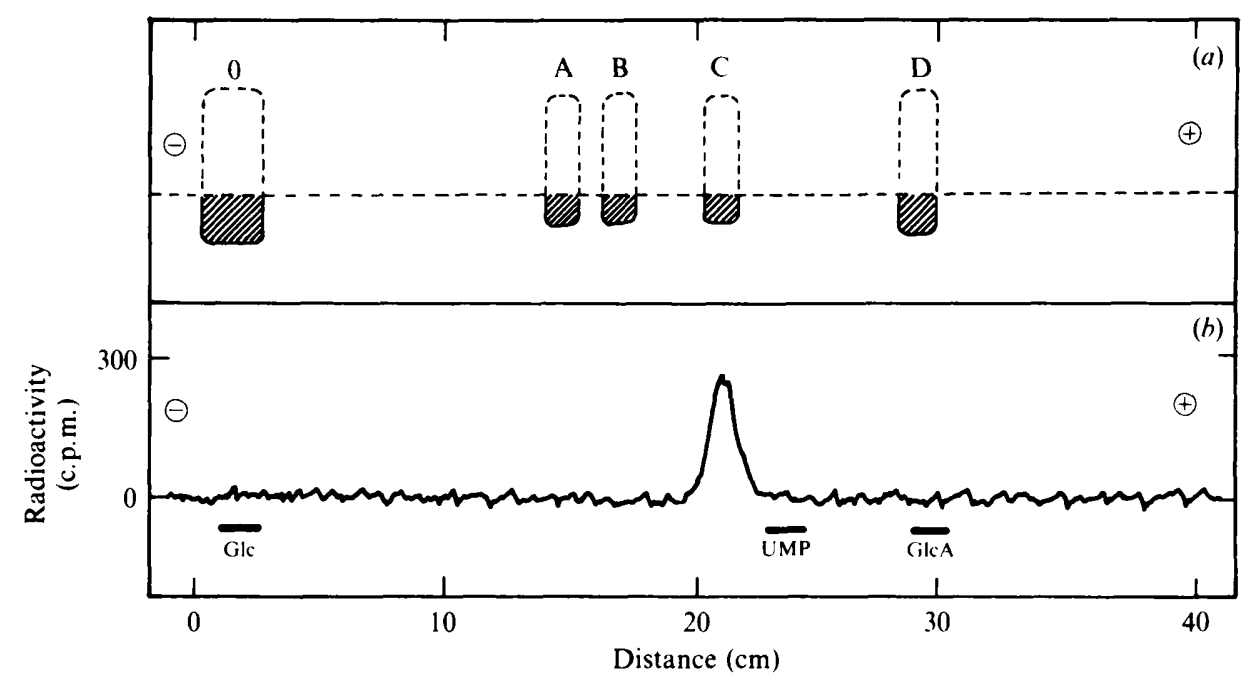

Fig. 5. Partial acid hydrolysis of acetan. A sample $(10 \mathrm{mg})$ of acetan was treated with $0 \cdot 1 \mathrm{M}-\mathrm{HCl}$ at $100{ }^{\circ} \mathrm{C}$ for $1 \mathrm{~h}$ (see Methods). The hydrolysis products were submitted to paper electrophoresis with buffer $\mathrm{A}$ to isolate the charged compounds. The paper was cut lengthwise (broken line in $a$ ) and the narrower strip developed for sugars to locate the different bands, which were eluted from the broad strip. $\left[{ }^{1+} \mathrm{C}\right]$ Glucuronic acid $(\beta 1-2)$ mannose from hexasaccharide prepared in vitro (see Methods) and unlabelled standards were run in a parallel strip $(b)$.

Partial acid hydrolysis. The products of partial acid hydrolysis of acetan were analysed by paper electrophoresis with buffer A, and five bands were observed (Fig. 5a): one was neutral (band 0 ) and four were negatively charged (A, B, C and D). Compound D was consistent with free glucuronic acid and compound $\mathrm{C}$ migrated like the $\left[{ }^{1+} \mathrm{C}\right]$ glucuronic acid-mannose standard $\left(R_{\mathrm{LMP}}=0 \cdot 9\right.$, Fig. $\left.5 b\right)$. Compound $\mathrm{C}$ was further characterized by paper chromatography (solvent $\mathrm{D}$ ) where it co-migrated with [ $\left.{ }^{1+} \mathrm{C}\right]$ glucuronic acid-mannose $\left(R_{\mathrm{Glc}}=0.5\right)$ and, after reduction with sodium borohydride, with $\left[{ }^{1+} \mathrm{C}\right]$ glucuronic acid-mannitol $\left(R_{\mathrm{Glc}}=0 \cdot 6\right)$. Also, treatment with $\beta$-glucuronidase released mannose and glucuronic acid as the only sugar residues. Therefore, compound $C$ was identified as the disaccharide glucuronic acid( $\beta 1-2)$ mannose (compound IV, Fig. 1), since TLC of the mannose derivative of the acetan permethylation products as well as the mass spectrum of the respective alditol acetate indicated that mannose was substituted at position 2 (rather than at position 6 as previously reported for the heptasaccharide diphosphate prenol precursors synthesized in vitro - see Discussion). Compounds $\mathrm{A}$ and $\mathrm{B}$, which were probably larger oligosaccharides, were not characterized.

The neutral band (Fig. $5 a$, band 0 ) was resolved into six bands upon paper chromatography with solvent $\mathrm{D}$ : three corresponded to glucose, mannose and rhamnose, respectively, and a fourth had the same mobility as gentiobiose (compound II, Fig. 1). Permethylation of this last compound followed by strong acid hydrolysis yielded two partially methylated residues, 2,3,4tri-O-methylglucose and 2,3,4,6-tetra- $O$-methylglucose, as judged by TLC with solvent $\mathrm{F}$. The identification of the fourth band as gentiobiose was confirmed by paper electrophoresis with buffer B ( $R_{\mathrm{Gic}}=0 \cdot 60$, identical to authentic gentiobiose) and by paper chromatography with solvent $\mathrm{D}$ and paper electrophoresis with buffer $\mathrm{C}$ of the borohydride-reduced material: in both systems it behaved as gentiobiitol $\left(R_{\text {(ilc }}=0.63\right.$ and $R_{\text {sorb }}=0.76$, respectively).

Relatively large amounts of acetan $(100 \mathrm{mg})$ were submitted to partial acid hydrolysis, to enable cellobiose (compound III, Fig. 1) to be detected in this neutral band 0 . The eluted band, with $\left[{ }^{1+} \mathrm{C}\right]$ cellobiose added as internal standard, was chromatographed with solvent $\mathrm{D}$ as before. The radioactive area which partially overlapped the gentiobiose band was eluted, reduced with $\mathrm{NaBH}_{4}$ and submitted to paper electrophoresis with buffer $\mathrm{C}$. The main band co-migrated with the radioactive cellobiitol $\left(R_{\text {sorb }}=0.33\right)$ and was clearly distinguished from gentiobiitol $\left(R_{\text {sorb }}=0 \cdot 76\right)$, also present. 


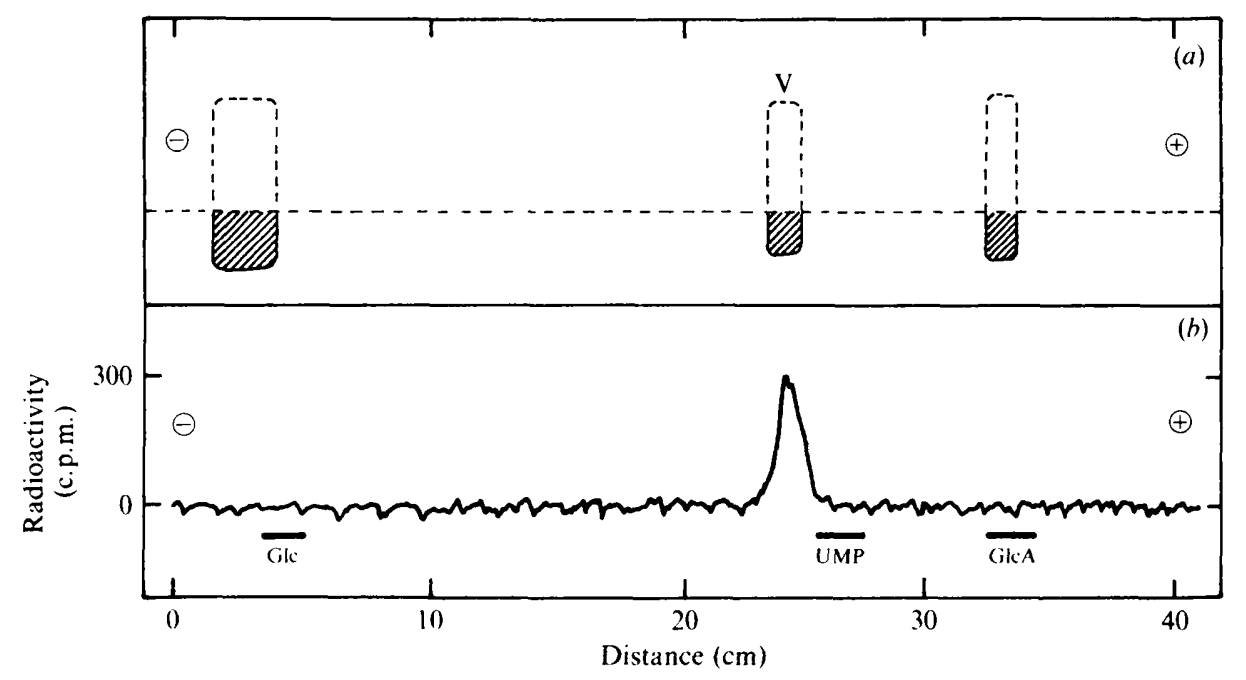

Fig. 6. Partial acetolysis of acetan. A sample of the polysaccharide $\left(7 \mathrm{mg}\right.$ ) was acetolysed at $63^{\circ} \mathrm{C}$ for $2 \mathrm{~h}$, as described by Kocourek \& Ballou (1969). The products were analysed by paper electrophoresis with buffer $A$ and located as indicated in the legend to Fig. 5 (part $a$ ). Unlabelled standards and a sample of authentic glucose $(\alpha \mid-4)\left[{ }^{14} \mathrm{C}\right]$ glucuronic acid were run in a parallel strip (part $b$ ).

Partial acetolysis. (i) Characterization of compound $V$. Partial acetolysis of the heptasaccharide synthesized in vitro produced only two charged compounds: glucuronic acid and a disaccharide characterized as Glc( $\alpha \mathrm{l}-4) \mathrm{GlcA}$ (compound V, Fig. 1) (Couso et al., 1982). The same substances were observed when acetan was acetolysed under identical conditions.

The acetolysis products, upon paper electrophoresis with buffer A, consisted of a neutral and two negatively charged bands (Fig. $6 a$ ). The faster-moving band ran as glucuronic acid and its identity was confirmed by paper chromatography with solvents $D$ and $E$ whereas the slowermoving band (compound $V$ ) had the same mobility as the glucose $(\alpha]-4)\left[{ }^{1+} \mathrm{C}\right]$ glucuronic acid standard $\left(R_{\mathrm{LMP}}=0 \cdot 9\right.$, Fig. $\left.6 h\right)$. Compound $\mathrm{V}$ also co-chromatographed with this standard in solvent $\mathrm{D}\left(R_{\mathrm{Glc}}=0.50\right)$ and upon paper electrophoresis with buffer $\mathrm{C}\left(R_{\mathrm{sorb}}=0.8\right)$. In the latter system, torohydride-reduced compound $\mathrm{V}$ behaved as glucose $(\alpha 1-4)\left[{ }^{1+} \mathrm{C}\right]$ glucuronitol $\left(R_{\text {sorb }}=1 \cdot 16\right)$. Finally, total acid hydrolysis of compound $\mathrm{V}$ liberated only glucose and glucuronic acid.

(ii) Characterization of compounds VI and VII. Acetolysis of acetan under milder conditions at $20^{\circ} \mathrm{C}$ for $48 \mathrm{~h}$ (Lawson \& Symes, 1977) led to the isolation of two neutral trisaccharides containing mannose and glucose. One was branched and was characterized as glucose( $\beta 1-4)$ [mannose( $\alpha 1-3)$ ]-glucose (compound VI, Fig. 1); the other was linear and identified as mannose $(\alpha 1-3)$ glucose $(\beta 1-4)$ glucose (compound VII, Fig. 1). The branched trisaccharide VI was characterized as follows. The acetolysis products were separated by paper electrophoresis with buffer $\mathrm{A}$ and the neutral band was recovered and paper chromatographed with solvent $\mathrm{D}$. In this system, several bands were observed, but only the one running in the trisaccharide area (compound VI) next to an internal standard of the linear trisaccharide $\left[{ }^{1+} \mathrm{C}\right]$ mannose $(\alpha 1-3) \operatorname{glucose}(\beta 1-4)$ glucose was considered (Fig. 7a). A portion of this material was hydrolysed in acid and chromatographed with solvent $\mathrm{E}$; only glucose and mannose were observed (not shown). Another portion was reduced with sodium borohydride and part of it was run in paper electrophoresis with buffer $C$, a system in which sorbitol substituted at position 3 does not migrate (Bourne et al., 1961). Practically all the material reacting with the silver reagent (reduced trisaccharide VI) remained in the neutral area (Fig. $7 b$ ) in the position corresponding to the branched $\left[{ }^{14} \mathrm{C}\right]$ glucose $(\beta 1-4)-[($ mannose- $\alpha 1-3)]\left[{ }^{14} \mathrm{C}\right]$ sorbitol standard. No bands were observed with the mobility of $\left[{ }^{1+} C\right]$ mannose $(\alpha 1-3)$ glucose $(\beta 1-4)$ sorbitol $\left(R_{\text {sorb }}=0.25\right)$. 


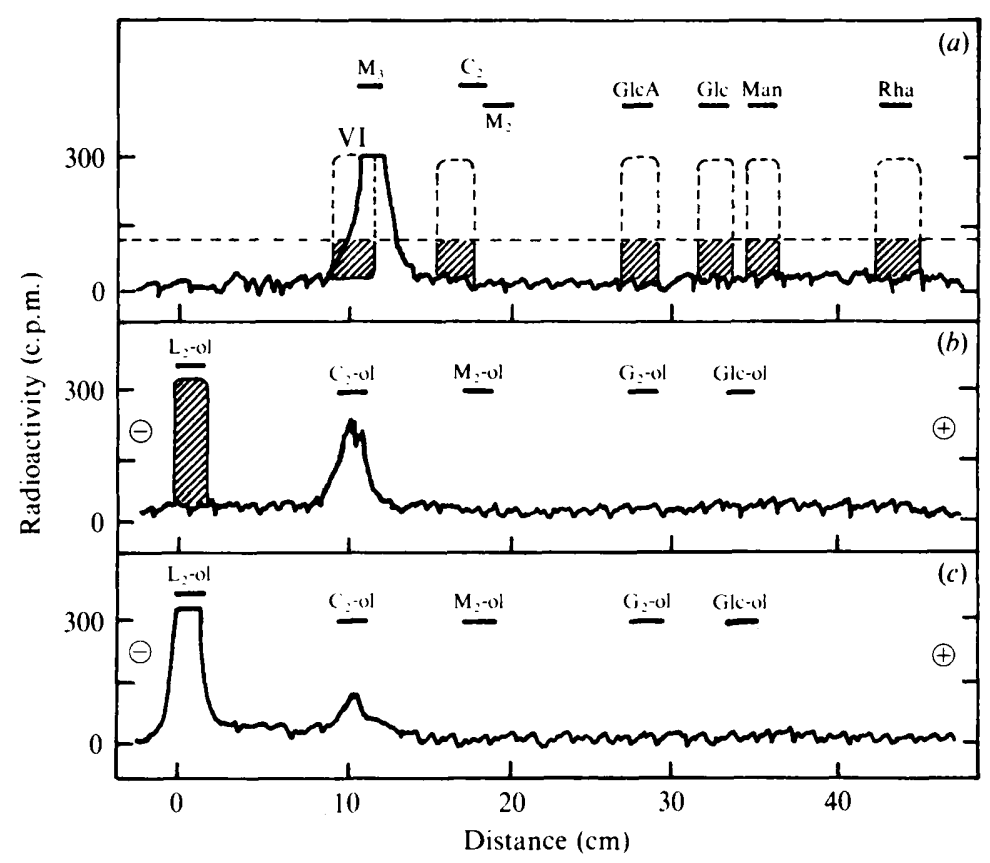

Fig. 7. Partial acetolysis of acetan. A sample of the polysaccharide $(50 \mathrm{mg})$ was acetolysed at $20^{\circ} \mathrm{C}$ for $48 \mathrm{~h}$, as described by Lawson \& Symes (1977). The neutral products, isolated by paper electrophoresis with buffer $A$ as in Fig. 6, were chromatographed with solvent $D$ and located as in Fig. 5. The trisaccharide $\left[{ }^{i+} \mathrm{C}\right]$ mannose $(\alpha 1-3)$ glucose $(\beta 1-4)$ glucose was added as an internal standard. Prior to developing the sugars, the paper strip was scanned for radioactivity to locate this compound $(a)$. The trisaccharide VI area was eluted and a sample of this material was borohydride-reduced and submitted to paper electrophoresis with buffer $\mathbf{B}(b)$. As above, the paper strip was scanned for radioactivity to locate [ $\left.{ }^{1+} \mathrm{C}\right]$ mannose $(\alpha \mathrm{l}-3)$ glucose $(\beta 1-4)$ sorbitol prior to developing the sugars. Part $(c)$ corresponds to a standard of $\left[{ }^{1+} C\right]$ glucose $(\beta 1-4)[\operatorname{mannose}(\alpha 1-3)]\left[{ }^{1+} \mathrm{C}\right]$ sorbitol slightly contaminated with mannose$(\alpha 1-3)\left[{ }^{1+} \mathrm{C}\right]$ glucose $(\beta 1-4)\left[{ }^{1+} \mathrm{C}\right]$ sorbitol run in parallel. $\mathbf{M}_{3}$, maltotriose; $\mathbf{M}_{2}$, maltose; $\mathbf{C}_{2}$, cellobiose ; $\mathbf{C}_{2-}$ ol, cellobiitol; $M_{2}$-ol, maltitol; $G_{2}$-ol, gentiobiitol; $L_{2}$-ol, laminiribiitol; Glc-ol, sorbitol.

In addition, trisaccharide VI was permethylated and hydrolysed with acid. TLC with solvent $\mathrm{F}$ of the products obtained showed the presence of 2,3,4,6-tetra- $O$-methylmannose, 2,3,4,6-tetra$O$-methylglucose and 2,6-di- $O$-methylglucose (not shown).

Another sample of reduced trisaccharide VI was partially hydrolysed $\left(0 \cdot 1 \mathrm{M}-\mathrm{HCl}, 100^{\circ} \mathrm{C}\right.$ for $30 \mathrm{~min}$ ) and chromatographed with solvent E. Four compounds were observed: undegraded trisaccharide, glucose, mannose and a 'disaccharide'. This latter material, upon paper electrophoresis with buffer $\mathrm{C}$, produced two components: one behaved as cellobiitol $\left(R_{\text {sorb }}=0.33\right)$ and the other was neutral, as expected for mannose(1-3)sorbitol. These two compounds were the only disaccharides that could be released by partial acid hydrolysis of compound VI (Fig. 1).

Hardly any material with the properties of the linear trisaccharide mannose $(\alpha 1-3)$ glucose$(\beta 1-4)$ glucose (compound VII, Fig. 1) was observed in this mild acetolysis experiment. For this reason, larger amounts of acetan $(200 \mathrm{mg})$ were acetolysed as above (at $20^{\circ} \mathrm{C}$ for $48 \mathrm{~h}$ ). In this case, the neutral products were isolated by filtration through a Dowex AG 1-X4 ( $\mathrm{AcO}^{-}$form) column, concentrated and paper chromatographed with solvent $D$. As in the previous experiment, in vitro-synthesized $\left[{ }^{1+} \mathrm{C}\right]$ mannose $(\alpha 1-3)$ glucose $(\beta 1-4)$ glucose $(7000$ c.p.m.) was added as internal standard. Five bands were observed (detected as described in the legend to Fig. 5). The slowest-moving band overlapped the radioactive area, and the next-faster one was in the disaccharide region. The remaining three bands co-chromatographed with glucose, mannose and rhamnose, respectively. The radioactive area was eluted, reduced with 
borohydride and the whole sample was analysed by paper electrophoresis with buffer $\mathrm{C}$. As before, most of the material moved to the neutral area, but a clear band was detected $\left(R_{\text {sorb }}=0.24\right)$, coincident with the radioactive standard. Two other bands were also observed ( $R_{\text {sorb }}=0.38$ and 0.58 , respectively), but not analysed further (not shown). The band of $R_{\text {sorb }}=0.24$ (compound VII, Fig. 1), rechromatographed with solvent D, produced only one silver-reagent-positive component, which carried all the radioactivity from the internal $\left[{ }^{1+} \mathrm{C}\right]$ mannose $(\alpha 1-3)$ glucose $(\beta 1-4)$ sorbitol as expected.

With this material, the anomeric configuration of the mannose-glucose linkage was investigated by incubations with $\alpha$-mannosidase. In order to trace the degradation products, borohydride-reduced $\left[{ }^{14} \mathrm{C}\right]$ glucose-labelled trisaccharide prepared in vitro was also added as an internal indicator of enzyme activity. Upon paper chromatography with solvent $D$, only mannose and cellobiitol were detected. The identity of the latter compound was confirmed by paper electrophoresis with buffer $C$. In this system maltitol moves faster $\left(R_{\text {sorb }}=0.53\right)$. From these results, the $\alpha$-configuration for the mannose is proposed and the $\beta-1,4$ bond for the glucoseglucose linkage in compound VII is confirmed.

\section{DISCUSSION}

The results presented indicate that $A$. xylinum NRRL B42 produces, in addition to cellulose, a complex exopolysaccharide for which we propose the name acetan. This polysaccharide has a structure that can be considered to be the result of the polymerization of the lipid-linked heptasaccharide synthesized in vitro by preparations of this organism (Couso et al., 1982). The sugar composition (Table 1), as well as the partial degradation products of both acetan and heptasaccharide, are basically identical (Figs 5 and 6). It should be mentioned that rhamnosecontaining oligosaccharides could not be isolated (Fig. 1) due to the known lability of the deoxysugar glycosidic linkage (Elderfield, 1945). Nevertheless, trimethylrhamnose was the only rhamnose derivative characterized after permethylation (Fig. 3), indicating a terminal position, as in the heptasaccharide prepared in vitro (Fig. 1). Similarly, the rhamnosyl(1-6)glucose linkage was assigned by analogy to what was known for the heptasaccharide (Couso et al., 1982), and in agreement with the characterization of $2,3,4,-$ tri- $O$-methylglucose among the permethylation products.

The configuration of the mannosyl(1-3)glucose linkage was investigated in some detail. In a previous paper (Couso et al., 1980) it was suggested that in the in vitro-synthesized trisaccharide mannose(1-3)glucose( $\beta 1-4)$ glucose the mannose configuration was $\beta$ because, using a commercial preparation containing $\alpha$ - and $\beta$-mannosidase activities and a partially purified $\alpha$ mannosidase from Jack bean, the latter enzyme failed to liberate mannose. These experiments have now been repeated with a carefully checked $\alpha$-mannosidase. The trisaccharide $\left[{ }^{1+} \mathrm{C}\right]$ mannose $(\alpha 1-3)$ glucose $(\beta 1-4)$ glucose, prepared in vitro with a $X$. campestris enzyme, was used as a control substrate (Ielpi et al., 1981). The trisaccharide prepared in vitro with the $A$. xylinum enzyme (Couso et al., 1980) was degraded by the $\alpha$-mannosidase at the same rate as the $X$. campestris trisaccharide. From these results, we now propose an $\alpha$-configuration for the mannosyl-glucose linkage of the in vitro-prepared $A$. xylinum oligosaccharide. This interpretation is in agreement with the results described in this paper for the equivalent trisaccharide (compound VII, Fig. 1) obtained by mild acetolysis of acetan: $\alpha$-mannosidase produced free mannose and the cellobiose derivative.

In a previous paper (Couso et al., 1982), dealing with labelled heptasaccharide diphosphate prenol precursors synthesized in vitro (tetra- and hexasaccharides), a 1,6 linkage was proposed for the glucuronic acid-mannose bond on the basis of lability to acetolysis (Kocourek \& Ballou, 1969) and liberation of formic acid upon periodate oxidation. However, in recent experiments, carried out with carefully purified $\left[{ }^{14} \mathrm{C}\right]$ mannose-labelled hexasaccharide, prepared from the respective lipid derivative obtained in vitro, no production of $\left[{ }^{14} \mathrm{C}\right]$ formic acid was observed, ruling out a 1,6 linkage. To make this point clear, the $\left[{ }^{14} \mathrm{C}\right]$ mannose-labelled hexasaccharide was permethylated, and after acid hydrolysis and TLC with solvent $G$ only 3,4,6-tri- $O$-methylmannose $\left(R_{\mathrm{M}}=0.55\right)$ was detected, indicating a 1,2 linkage. In this system, 2,3,4-tri- $O$ - 
methylmannose ( $\left.R_{\mathrm{N}}=0.61\right)$ and the other two tri- $O$-methyl derivatives (2,3,6- and 2,4,6-tri- $O$ methylmannose) run further (Chapman et al., 1979). On the other hand, the lability to acetolysis of the glucuronic acid-mannose linkage was confirmed. This lability, hitherto considered to be characteristic of 1,6 bonds (Kocourek \& Ballou, 1969), was in agreement with results reported for xanthan gum, in which the glucuronic acid $(\beta 1-2)$ mannose linkage is also easily split by this degradation technique (Lawson \& Symes, 1977).

Partial acetolysis of acetan also led to the isolation and identification of the branched trisaccharide glucose $(\beta 1-4)[$ mannose $(\alpha 1-3)]$ glucose (trisaccharide VI, Figs 1 and 7 ), a compound that had not been previously isolated from the in vitro-prepared heptasaccharide diphosphate prenol degradation products. The interpretation of this result is simple: the branching arises as a consequence of the polymerization process in which the first glucose of a heptasaccharide repeating unit is bound to the second glucose of another repeating unit, creating a new $\beta-1,4$ bond. Obviously, this branch is not present in the heptasaccharide precursor (Fig. 1).

A similar process has been observed in the biosynthesis of xanthan gum, in which the lipidlinked pentasaccharide is polymerized at the level of the second glucose, creating a $\beta$-1,4-glucan main chain with trisaccharide branches every two glucoses, as mentioned above. The similarity of acetan to xanthan gum is such that the first four sugars and linkages of both repeating units are identical (Figs 1 and 2). X-ray analysis of acetan fibres also reveals a structure strikingly similar to that of xanthan gum (E. Smolko, unpublished observations).

Xanthan gum contains also non-glycosidic substituents such as acetyl and pyruvate ketal (Jansson et al., 1975; Melton et al., 1976). For acetan, only one or two acetyl residues per repeat unit were detected but their position was not determined. Other substituents such as succinate, formate, pyruvate ketal or methyl residues were not found.

In addition to cellulose, several other exopolysaccharides have been reported to be produced by different $A$. xylinum strains: $\alpha$-glucans (Dekker et al., 1977), $\beta$-glucans (Colvin et al., 1979; Sandermann \& Dekker, 1979; Amemura et al., 1985) and a complex non-cellulosic polysaccharide containing glucose, mannose, rhamnose and glucuronic acid in a molar ratio $3: 1: 1: 1$, the latter being released by a cellulose-negative strain (Valla \& Kjosbakken, 1981). The same sugars, but in a different ratio, 2-8:1:2:2, are present in an acidic polysaccharide recently described in two strains of $A$. xylinum (Amemura et al., 1985). The isolation of a noncellulose-producing Acetobacter sp. that liberates a polysaccharide containing glucose, galactose, mannose and glucuronic acid in an approximate molar ratio of $6: 2: 1: 1$ has also been reported (Minakami et al., 1984).

Not all the tested strains of $A$. xylinum produce acetan. Furthermore, the available evidence indicates a direct correlation between acetan production and in vitro synthesis of lipid-linked heptasaccharide, reinforcing the role of precursor assigned to the latter (N. I. de Iannino \& M. Dankert, unpublished).

This paper is dedicated to Dr Luis F. Leloir on the occasion of his 80th birthday.

The authors gratefully acknowledge Dr Leloir and other members of the Institute for continuous advice and criticism. Drs R. Ugalde, R. Wolosiuk and Nora Inon de Iannino are specially thanked for reading this manuscript, and Susana Raffo and Marta Bravo for the excellent technical assistance in the preparation of labelled sugar nucleotides. The authors also wish to express their gratitude to Dr Eduardo Gros from the Department of Organic Chemistry, School of Science, University of Buenos Aires, for carrying out the gas chromatography and mass spectrometry analyses. M.A.D. is a Career Investigator of the Consejo Nacional de Investigaciones Cientificas y Tecnicas (Argentina).

\section{REFERENCES}

Aloni, Y., Cohen, R., Benziman, M. \& Delmer, D. P (1983). Solubilization of the UDP-glucose : 1,4- $\beta$-Dglucan 4- $\beta$-D-glucosyltransferase (cellulose synthase) from Acetobacter xylinum. A comparison of regulatory properties with those of the membrane-bound form of the enzyme. Journal of Biological Chemistry 258, 4419-4423.
Alperin, D. M., Carminatti, H., Idoyaga-Vargas, V. \& Couso, R. (1983). Thermal-ultraviolet method for differential detection and recovery of organic compounds in thin-layer chromatography. Journal of Chromatography 265, 193-200.

Amemura, A., Hashimoto, T., Koizumi, K. \& UTAMURA, T. (1985). Occurrence of extracellular 
$(1 \rightarrow 2)-\beta$-D-glucans and $(1 \rightarrow 2)-\beta$-D-gluco-oligosaccharides in Acetobacter. Journal of General Microbiology 131, 301-307.

Bartnicki-Garcia, S. \& Lindberg, B. (1972). Partial characterization of mucoran: the glucuronomanan component. Carbohydrate Research 23, 75-85.

Blumenkrantz, N.\& Asboe-Hansen, G. (1973). New method for quantitative determination of uronic acid. Analytical Biochemistry 54, 484-489.

Bourne, E. J., Hutson, D. H. \& Weigel, H. (1961). Complexes between molybdate and acyclic polyhydroxy compounds. Journal of the Chemical Society, Part I, 35-38.

Chapman, A., Li, E. \& Kornfeld, S. (1979). The biosynthesis of the major lipid-linked oligosaccharide of Chinese hamster ovary cells occurs by the ordered addition of mannose residues. Journal of Biological Chemistry. 254, 10243-10249.

Colvin, J. R., Sowden, L. C., Daoust, V. \& Perry, M. (1979). Additional properties of a soluble polymer of glucose from cultures of Acetobacter rylinum. Canadian Journal of Biochemistry 87, 1284 1288.

Couso, R. O., IElpi, L., Garcia, R. C. \& Dankert, M. A. (1980). Synthesis of mannosyl cellobiose diphosphate prenol in Acetobacter xylinum. Archives of Biochemistry and Biophysics 204, 434-443.

Couso, R. O., Ielpi, L., Garcia, R. C. \& Dankert, M. A. (1982). Biosynthesis of polysaccharides in Acetobacter xylinum. Sequential synthesis of a heptasaccharide diphosphate prenol. European Journal of Biochemistry 123, 617-627.

Davidson, E. A. (1966). Analysis of sugars found in mucopolysaccharides. Methods in Enzymology 8, 5260.

Dekker, R. F. H., Rietschel, E. Th. \& SandermanN, H., JR (1977). Isolation of $\alpha$-glucan and lipopolysaccharide fractions from Acetohacter xylinum. Archives of Microbiology 115, 353-357.

DElmER, D. P. (1983). Biosynthesis of cellulose. Advances in Carbohydrate Chemistry and Biochemistry 41, 105-153.

DisCHE, Z. \& Shettles, L. B. (1948). A specific color reaction of methylpentoses and a spectrophotometric micromethod for their determination. Journal of Biological Chemistry 175, 595-603.

ELDERFIELD, R. C. (1945). The carbohydrate components of the cardiac glycosides. Advances in Carbohydrate Chemistry 1, 147-150.

Garcia, R. C., Recondo, E. \& Dankert, M. A. (1974). Polysaccharide biosynthesis in Acetobacter xylinum. Enzymatic synthesis of lipid diphosphate and monophosphate sugars. European Journal of Biochemistry 43, 93-105.

GLASER, L. (1958). The synthesis of cellulose in cell-free extracts of Acetobacter xylinum. Journal of Biological Chemistry 232, 627-636.

HeSTRIN, S. (1949). The reaction of acetylcholine and other carboxylic acid derivatives with hydroxylamine and its analytical application. Journal of Biological Chemistry 180, 249-261.

Hestrin, S. \& Schramm, M. (1954). Synthesis of cellulose by Acetobacter xylinum. Preparation of freeze-dried cells capable of polymerizing glucose to cellulose. Biochemical Journal 58, 345-352.
Holzwarth, G. (1976). Conformation of the extracellular polysaccharide of Xanthomonas campestris. Biochemistry 15, 4333-4339.

IElPI, L., Couso, R. O. \& Dankert, M. A. (1981). Lipid-linked intermediates in the biosynthesis of xantham gum. FEBS Letters 130, 253-256.

JANSSON, P. E., Kenne, L. \& LindBerG, B. (1975). Structure of the extracellular polysaccharide from Xanthomonas campestris. Carbohydrate Research 45 , 275-282.

Jones, T. M. \& Albersheim, P. (1972). A gas chromatographic method for the determination of aldose and uronic acid constituents of plant cell wall polysaccharides. Plant Physiology 49, 926-936.

Kocourek, J. \& Ballou, C. E. (1969). Method for fingerprinting yeast cell wall mannans. Journal of Bacteriology 100, 1175-1181.

LAWSON, C. J. \& SYMES, K. C. (1977). Oligosaccharides produced by partial acetolysis of xanthan gum. Carbohydrate Research 58, 433-438.

LI, E., TABas, I. \& Kornfeld, S. (1978). The synthesis of complex-type oligosaccharides. Structure of the lipid-linked oligosaccharide precursor of the complex-type oligosaccharides of the vesicular stomatitis virus $G$ protein. Journal of Biological Chemistry 253, 7762-7770.

LINDBERG, B. (1972). Methylation analysis of polysaccharides. Methods in Enzymology 28, 178-195.

Lloyd, J. B. \& Whelan, W. J. (1969). An improved method for enzymic determination of glucose in the presence of maltose. Analytical Biochemistry 30, 467470.

Melton, L. D., Mindt, L., Rees, D. A. \& Sanderson, G. R. (1976). Covalent structure of the extracellular polysaccharide from Xanthomonas campestris: evidence from partial hydrolysis studies. Carbohydrate Research 46, 245-257.

Minakami, H., Entani, E., Tayama, K., Fujiyama, S. \& MASAI, H. (1984). Isolation and characterization of a new polysaccharide-producing Acetobacter sp. Agricultural and Biological Chemistry 48, 24052414.

SandermanN, H., JR \& DekKer, R. F. H. (1979). $\beta$-1,2Glucosyltransfer by membrane preparations from Acetobacter xylinum. FEBS Letters 107, 237-240.

SANDFORD, P. A. \& CONRAD, H. E. (1966). The structure of the Acetobacter aerogenes A3 (SI) polysaccharide. I. A reexamination using improved procedures for methylation analysis. Biochemistry $\mathbf{5}$, $1508-1517$.

Sandford, P. A., Pittsley, J. E., Knutson, C. A., Watson, P. R., Cadmus, M. C. \& Jeanes, A. (1977). Variation in Xanthomonas campestris NRRL B1459: characterization of xanthan products of differing pyruvic acid content. In Extracellular Microbial Polysaccharides (ACS Symposium Series no. 45), p. 192-210. Edited by P. A. Sandford \& A. Laskin. Washington, DC: American Chemical Society.

Smith, F. \& Montgomery, R. (1956). End group analysis of polysaccharides. In Methods of Biochemical Analysis, vol. 3, pp. 154-157. Edited by D. Glick. New York \& London: Interscience.

SuTHERLAND, I. W. (1969). Structural studies on colanic acid, the common exopolysaccharide found 
in the Enterobacteriaceae, by partial acid hydrolysis. Oligosaccharides from colanic acid. Biochemical Journal 115, 935-945.

Trevelyan, W. E., Procter, D. P \& Harrison, J. S. (1950). Detection of sugars on paper chromatograms. Nature, London 166, 444-445.

Valent, B. S., Darvill, A. G., McNeIl, M., RobertSEN, B. K. \& Albersheim, P. (1980). A general and sensitive chemical method for sequencing the glycosyl residues of complex carbohydrates. Carbohydrate Research 79, 165-192.

VALLA. S. \& KJOSBAKKEN, J. (1981). Isolation and characterization of a new extracellular polysaccharide from a cellulose-negative strain of Acetobacter .rylinum. Canadian Journal of Microbiology 27, 599 603. 